Article

\title{
Copper Electrodeposition on a Magnesium Alloy (AZ80) with a U-Shaped Surface
}

\author{
Ching An Huang *, Yu Hu Yeh, Che Kuan Lin and Chen Yun Hsieh \\ Department of Mechanical Engineering, Chang Gung University, Taoyuan 333, Taiwan; \\ E-Mails: d9922005@stmail.cgu.edu.tw (Y.H.Y.); cklin918@gmail.com (C.K.L.); \\ ff127511@gmail.com (C.Y.H.)
}

* Author to whom correspondence should be addressed; E-Mail: gfehu @ mail.cgu.edu.tw; Tel.: +886-3-211-8800 (ext. 5655); Fax: +886-3-211-8050.

External Editor: Peter J. Uggowitzer

Received: 14 May 2014; in revised form: 9 October 2014 / Accepted: 6 November 2014 /

Published: 14 November 2014

\begin{abstract}
Cu}$ electrodeposition was performed on a cylindrical AZ80 substrate with a U-shaped surface. A uniform deposition of $\mathrm{Cu}$ was achieved on an AZ80 electrode via galvanostatic etching, followed by $\mathrm{Cu}$ electrodeposition in an eco-friendly alkaline $\mathrm{Cu}$ plating bath. Improper wetting and lower rotational speeds of the AZ80 electrode resulted in an uneven $\mathrm{Cu}$ deposition at the inner upper site of the U-shaped surface during the $\mathrm{Cu}$ electroplating process. This wetting effect could be deduced from the variation in the anodic potential during the galvanostatic etching. The corrosion resistance of the $\mathrm{Cu}$-deposited AZ80 electrode can be considerably improved after Ni electroplating.
\end{abstract}

Keywords: metal and alloys; thin films; corrosion; electrochemical reactions

\section{Introduction}

The potential applications of engineering light materials, such as $\mathrm{Mg}, \mathrm{Al}$, and $\mathrm{Ti}$ alloys, has attracted much more attention in recent years, because weight reduction of electronic and automobile components is strongly needed in order to reduce energy consumption. Among these materials, components made of $\mathrm{Mg}$ alloys have relatively low weights. Moreover, $\mathrm{Mg}$ alloys have some outstanding advantages, such as high strength to weight ratio, high thermal conductivity, superior 
damping capacity, good electromagnetic shielding and facile recycling. Thus, $\mathrm{Mg}$ alloys have been widely used as construction materials in the automotive, computer, aerospace, hand tool and cell phone industries. However, $\mathrm{Mg}$ alloys show poor corrosion and wear resistance, which limits their widespread usage [1]. Thus, surface treatments are necessary to improve these properties in $\mathrm{Mg}$ alloys. Several surface treatments have been proposed to meet the requirements of corrosion protection for $\mathrm{Mg}$ alloys, such as metal electroplating [2,3], conversion coatings [4,5], anodising [6], micro-arc oxidation treatment [7,8], organic coatings [9] and vapour-phase processes [10]. Of these different surface treatments, electroplating is a relatively economical and convenient method. Therefore, it is worthwhile to develop a suitable protective coating method, such as $\mathrm{Ni}, \mathrm{Ni} / \mathrm{Cu}$, and $\mathrm{Cr} / \mathrm{Cu}$ coatings, for electroplating of magnesium alloys.

$\mathrm{Mg}$ alloys are easily corroded in water or oxidised in air [1]. Because of its low electrical conductivity and bonding ability, this corroded surface or oxide layer could impede further electroplating of the surface. Several pretreatments on the surface of the $\mathrm{Mg}$ alloy have been proposed for electroplating. Many reports have shown that the activation of the $\mathrm{Mg}$ alloy can be accomplished first by mechanical polishing, then by dipping in an alkaline solution, and finally by treatment in an acid bath containing chromic acid or hydrofluoric acid [11,12]. In our previous work, we have shown that $\mathrm{Cu}$ deposition could be achieved on the surface of a $\mathrm{Mg}$ alloy using a pretreatment of galvanostatic etching followed by electroplating in an eco-friendly $\mathrm{Cu}$-alkaline plating bath $[13,14]$. The activation of the surface of the $\mathrm{Mg}$ alloy could be deduced from the variation in the anodic potential during the galvanostatic etching. We found that an activated $\mathrm{Mg}$ alloy surface was obtained when the anodic potential increased to a clear potential plateau during the galvanostatic etching process. After etching in the potential plateau, the oxides and the autocatalytically deposited $\mathrm{Cu}$ layer on top of the $\mathrm{Mg}$ alloy could be removed, leading to an activated surface available for further $\mathrm{Cu}$ electroplating [13-15].

In this study, a Mg alloy (AZ80) bar was shaped into a cylinder with a U-shaped surface. The AZ80 cylindrical electrode was used as the substrate for galvanostatic etching and $\mathrm{Cu}$ electroplating in an eco-friendly alkaline $\mathrm{Cu}$ plating bath. The influence of the wetting properties and the rotational speed on the coverage of the $\mathrm{Cu}$ deposition on a U-shaped surface is discussed. In addition, the corrosion resistance of uncoated and coated AZ80 is electrochemically evaluated.

\section{Experimental Section}

A bar of as-rolled magnesium alloy (AZ80) with a diameter of $13 \mathrm{~mm}$ was used in this study. The chemical composition of the AZ80 specimen was $8.5 \% \mathrm{Al}, 0.5 \% \mathrm{Zn}$ and $0.12 \% \mathrm{Mn}$ with the remainder composed of Mg. Electroplating was conducted in a two-electrode cell. The AZ80 specimen was used as the electroplating substrate and shaped into a rotating cylinder electrode (RCE) with a diameter of $10 \mathrm{~mm}$ and a length of $6.7 \mathrm{~mm}$. Figure 1 shows the dimension of AZ80 RCE with a U-shaped surface. A platinized Ti-mesh was used as the counter electrode. The AZ80 RCEs were cut into a U shape using a lathe machine to achieve a U-shaped surface for galvanostatic etching and $\mathrm{Cu}$ electroplating. The surface of the AZ80 RCE specimen was mechanically dry-ground with a 600-grit emery paper, ultrasonically cleaned in de-ionised water, and was subjected to galvanostatic etching followed by $\mathrm{Cu}$ electroplating in an alkaline $\mathrm{Cu}$ plating bath. Before electroplating, galvanostatic etching with an anodic current density of $20 \mathrm{~mA} \cdot \mathrm{cm}^{-2}$ for $120 \mathrm{~s}$ was performed in an alkaline $\mathrm{Cu}$ sulphate plating bath 
to activate the surface of the AZ80 RCE. The alkaline $\mathrm{Cu}$ sulphate bath contained $40 \mathrm{~g} / \mathrm{L} \mathrm{CuSO}_{4}$, $150 \mathrm{~g} / \mathrm{L} \mathrm{KNaC} \mathrm{H}_{4} \mathrm{O}_{6}, 20 \mathrm{~g} / \mathrm{L} \mathrm{H}_{3} \mathrm{BO}_{3}$ and enough $\mathrm{NaOH}$ to maintain $\mathrm{pH} 10$.

Figure 1. Dimensions of the AZ80 RCE with a U-shaped surface used in this study.
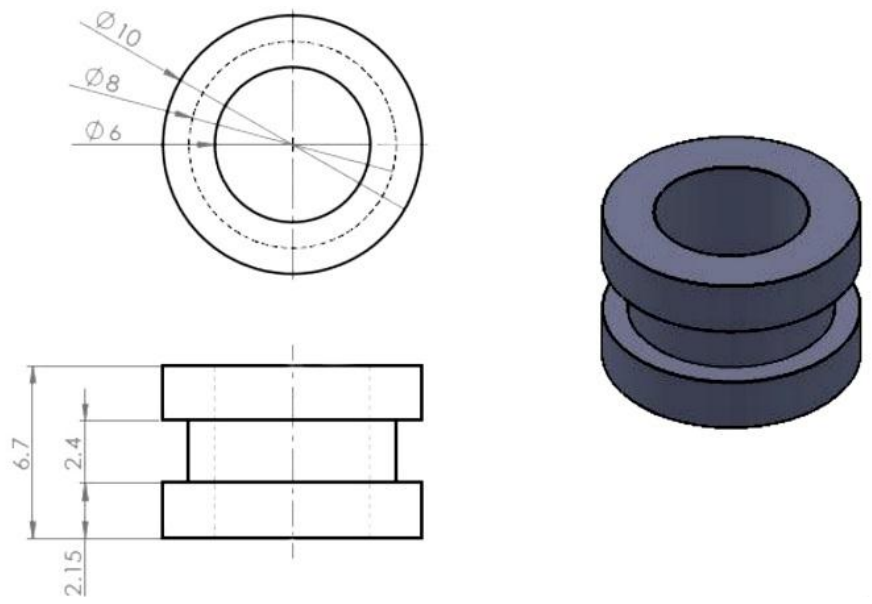

To obtain a $\mathrm{Cu}$ film with a thickness of approximately $3 \mu \mathrm{m}$, the AZ80 cylindrical electrode was electroplated in an alkaline $\mathrm{Cu}$ sulphate bath with a current density of $40 \mathrm{~mA} \cdot \mathrm{cm}^{-2}$ for $600 \mathrm{~s}$. After $\mathrm{Cu}$ electroplating in the alkaline solution, the AZ80 specimen was further electroplated in an acidic $\mathrm{Cu}$ plating bath with a current density of $40 \mathrm{~mA} \cdot \mathrm{cm}^{-2}$ for $410 \mathrm{~s}$ to effectively increase the thickness of the $\mathrm{Cu}$ deposition film to approximately $9 \mu \mathrm{m}$.

To evaluate the bonding strength between the $\mathrm{Cu}$ film and the AZ80 substrate, the Standard Test Method for Measuring Adhesion by Tape Test, or the ISO 2409 [16], was performed on the Cu-treated AZ80 specimens. The test was performed by scratching six parallel lines with a width of $1 \mathrm{~mm}$ in both longitude and latitude on top of the Cu-deposited AZ80 using a diamond knife. The scratched specimen was tightly adhered to a 3M adhesive tape (3M Company, Core Series 4-1000) for approximately $60 \mathrm{~s}$, and it was subsequently peeled off rapidly in the direction parallel to the deposition surface. The bonding strength can be evaluated from the appearance of the coated specimen upon peeling. When the bonding strength is poor, the deposited film is broken and peeled from the specimen; conversely, when the bonding strength is good, only scratch marks are revealed on the surface of the specimen. According to the ISO 2409 [16], the bonding strength could be categorised into six grades from 0 to 5 in which a lower grade number corresponds to a higher bonding strength between the deposit and the substrate.

The corrosion resistance of uncoated and coated AZ80 specimens was examined by anodic polarisation measurements in a $0.1 \mathrm{M} \mathrm{H}_{2} \mathrm{SO}_{4}$ solution. The anodic polarisation test was conducted in a typical electrochemical three-electrode cell. The uncoated or coated AZ80 specimen was used as the working electrode. A platinized Ti-mesh and an $\mathrm{Ag} / \mathrm{AgCl}$ electrode in a saturated $\mathrm{KCl}$ solution were used as the counter and reference electrodes, respectively. The anodic polarisation behaviour of the uncoated and coated AZ80 specimens was evaluated by potentiodynamic scanning with a scan rate of $5 \mathrm{mV} \cdot \mathrm{s}^{-1}$ from $-0.25 \mathrm{~V}$ (vs. open circuit potential) to the noble potential until the breakdown of the coating. The corrosion potential and corrosion current density of an uncoated or coated AZ80 
specimen were estimated from its anodic polarization. It can be expected that the specimen with a lower corrosion current density could have a higher corrosion resistance.

Morphologies of the coated AZ80 were examined with an optical microscope (OM, Olympus BH2-UMA, Olympus Ltd., Tokyo, Japan) and a scanning electron microscope (SEM, HITACH S-3000N, Hitach Ltd., Tokyo, Japan) equipped with an energy-dispersive X-ray spectrometer (EDS), which allows chemical composition analysis.

\section{Results and Discussion}

\subsection{Effect of the Rotation Speed of AZ80 RCE}

To study the effect of the rotation speed on the surface activation process, the AZ80 RCE was galvanostatically etched at a rotation speed that was varied from 300 to $2000 \mathrm{rpm}$. Figure 2 shows the anodic potential variation of the AZ80 RCE at different rotating speeds during galvanostatic etching in the alkaline $\mathrm{Cu}$ plating bath. A distinct potential plateau was clearly found in the potential variation curve when the rotation speed was $1000 \mathrm{rpm}$ or greater. As shown in Figure 2, the galvanostatic etching period, marked from the beginning to the potential plateau, increased with increasing rotation speeds. At a rotation speed of below $500 \mathrm{rpm}$, the anodic potential increased steadily in a relatively shorter time, and the potential plateau was not clearly observed. In our previous study [13], we found that the activation of the surface of a Mg alloy specimen could be achieved when the anodic potential increased to the potential plateau during galvanostatic etching. With further galvanostatic etching from the potential plateau, an obvious increase in anodic potential could be seen. The potential increase is attributed to the formation of a dense oxide on $\mathrm{Mg}$ alloy specimen. This indicates that the $\mathrm{Cu}$ electroplating on the AZ80 RCE must be conducted at a rotational speed of $1000 \mathrm{rpm}$ or more. The activated surface could be further treated with $\mathrm{Cu}$ in the alkaline $\mathrm{Cu}$ plating bath. This finding indicates that in order to obtain a well-adhering $\mathrm{Cu}$ film on the AZ80 RCE, the rotation speed of the AZ80 RCE must be $1000 \mathrm{rpm}$ or greater during the galvanostatic etching and $\mathrm{Cu}$ electroplating in the alkaline $\mathrm{Cu}$ plating bath.

Figure 2. Potential variation of the AZ80 RCE at different rotation speeds during the galvanostatic etching at the current density of $20 \mathrm{~mA} \cdot \mathrm{cm}^{-2}$ in an alkaline $\mathrm{Cu}$ plating bath.

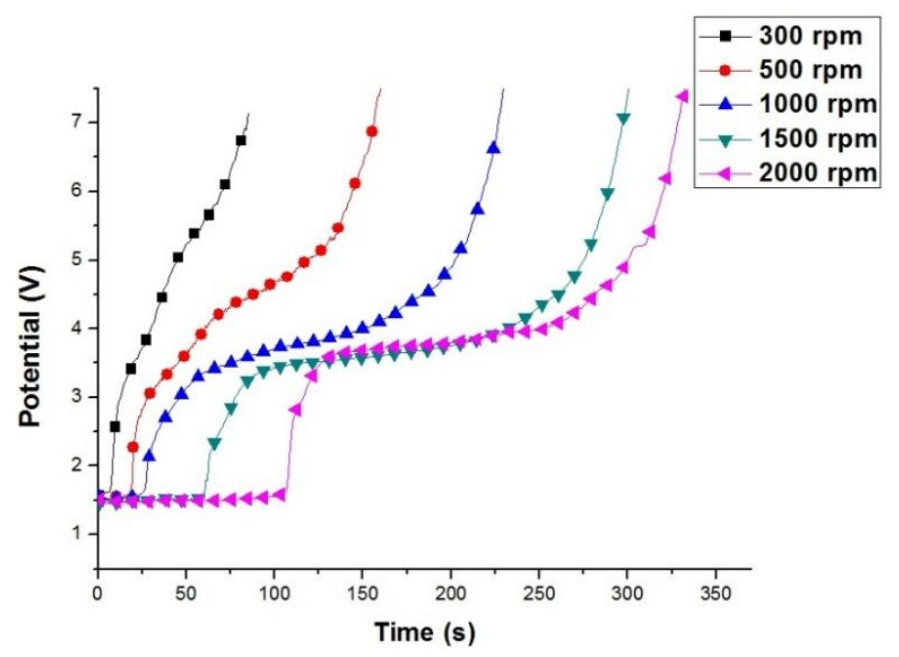


Figure 3 demonstrates the potential variation of the AZ80 RCE at different rotation speeds during galvanostatic etching followed by $\mathrm{Cu}$ electroplating in the alkaline $\mathrm{Cu}$ plating bath. Although a potential plateau was not observed, the galvanostatic etching of the AZ80 RCE at a rotation speed of $500 \mathrm{rpm}$ was conducted at a potential roughly corresponding to the potential plateau observed at a rotation speed of above $1000 \mathrm{rpm}$. As shown in Figure 3, the $\mathrm{Cu}$ electroplating at $300 \mathrm{rpm}$ has an obvious potential offset of $c a$. $-0.6 \mathrm{~V}$. This indicates that an oxide would exist on the AZ80 RCE, leading to a little increase in cathodic potential. To evaluate the bonding strength between the $\mathrm{Cu}$ deposit and the AZ80 RCE, Cu electrodeposition with a plating current density of $40 \mathrm{~mA} \cdot \mathrm{cm}^{-2}$ was performed for $600 \mathrm{~s}$ after galvanostatic etching. Therefore, the $\mathrm{Cu}$-deposited AZ80 RCEs were prepared at different rotation speeds for the bonding strength test.

Figure 3. Potential variation of the AZ80 RCE at different rotation speeds during galvanostatic etching at the current density of $20 \mathrm{~mA} \cdot \mathrm{cm}^{-2}$ followed by $\mathrm{Cu}$ electrodeposition at the current density of $40 \mathrm{~mA} \cdot \mathrm{cm}^{-2}$ in an alkaline $\mathrm{Cu}$ plating bath.

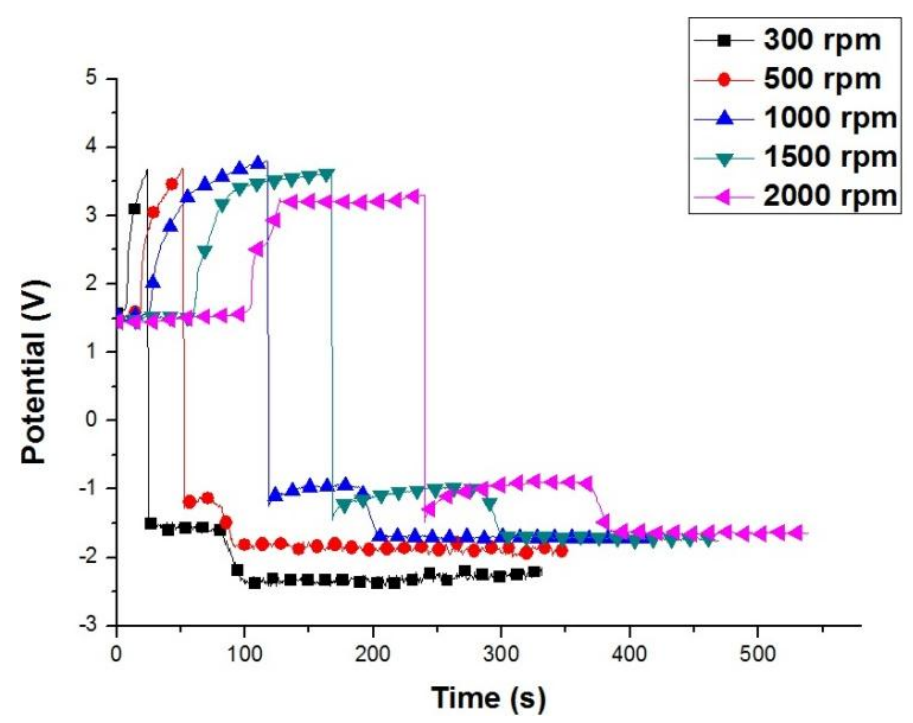

Figure $4 \mathrm{a}-\mathrm{d}$ shows the morphologies of the $\mathrm{Cu}$-deposited AZ80 RCEs prepared at rotation speeds of 300, 500, 1000 and 2000 rpm, respectively. As shown in Figure 4a,b, some blisters were observed on the $\mathrm{Cu}$-deposited AZ80 RCEs prepared at rotation speeds of 300 and $500 \mathrm{rpm}$, while a uniform $\mathrm{Cu}$ film was observed on the AZ80 RCE at a rotation speed of $1000 \mathrm{rpm}$ or greater (see Figure 4c,d). This result indicates that the bonding strength between the $\mathrm{Cu}$ deposition film and the AZ80 RCE could be increased significantly by increasing the rotation speed from 500 to $1000 \mathrm{rpm}$.

Figure 5a,b shows the surface morphologies of the Cu-treated AZ80 RCEs, which were galvanostatically etched and $\mathrm{Cu}$-treated at rotation speeds of 500 and $1000 \mathrm{rpm}$ in the alkaline $\mathrm{Cu}$ plating bath as described in the bonding strength test, known as the ISO 2409 [16]. As expected, a poor adhesion strength with an ISO grade of 5 was observed between the $\mathrm{Cu}$ deposit and the AZ80 substrate for the $\mathrm{Cu}$-deposited AZ80 RCE electroplated at $500 \mathrm{rpm}$ (see Figure 5a). In contrast, an obviously high bonding strength with an ISO grade of 0 was detected for the sample prepared at $1000 \mathrm{rpm}$ (see Figure $5 \mathrm{~b}$ ). These results of the bonding strength test are in full agreement with the galvanostatic etching observations discussed earlier. That is, a potential plateau was not clearly found during galvanostatic etching when the rotation speed of the AZ80 RCE was at $500 \mathrm{rpm}$, while the potential 
plateau was clearly observed at $1000 \mathrm{rpm}$. An activated surface for $\mathrm{Cu}$ electrodeposition could be obtained when the rotation speed of the AZ80 RCE was $1000 \mathrm{rpm}$ or greater. To study the $\mathrm{Cu}$ electrodeposition behaviour, the AZ80 RCE with a U-shaped surface was galvanostatically etched and was electroplated with $\mathrm{Cu}$ at a rotation speed of $1000 \mathrm{rpm}$ in the alkaline $\mathrm{Cu}$ plating bath.

Figure 4. Surface morphology of the AZ80 RCE after galvanostatic etching at the current density of $20 \mathrm{~mA} \cdot \mathrm{cm}^{-2}$ and Cu-electroplating at the current density of $40 \mathrm{~mA} \cdot \mathrm{cm}^{-2}$ at rotation speeds of (a) 300; (b) 500; (c) 1000; and (d) $2000 \mathrm{rpm}$.

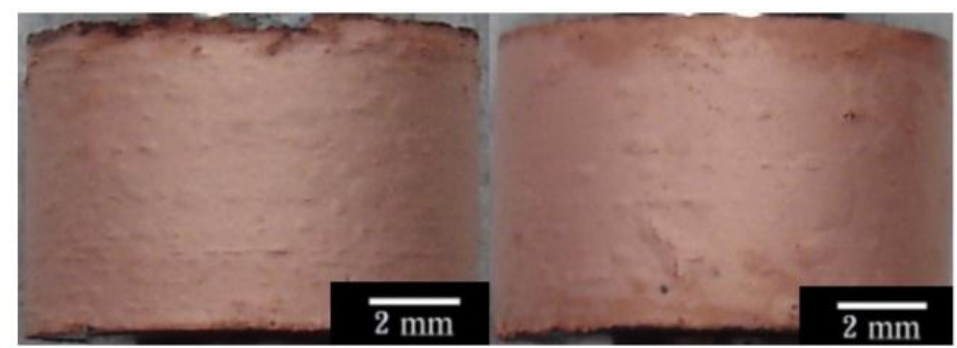

(a)

(b)

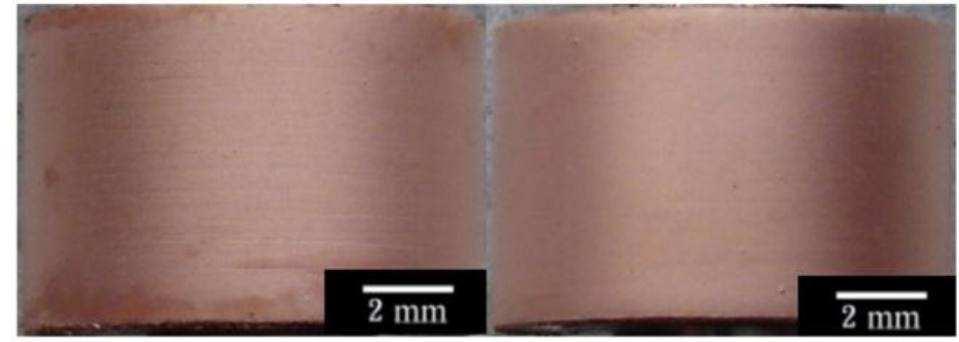

(c)

(d)

Figure 5. Surface morphology of the AZ80 RCE galvanostatically etched at the current density of $20 \mathrm{~mA} \cdot \mathrm{cm}^{-2}$ and Cu-electroplated at the current density of $40 \mathrm{~mA} \cdot \mathrm{cm}^{-2}$ at rotation speeds of (a) 500, and (b) $1000 \mathrm{rpm}$ after the bonding strength test.

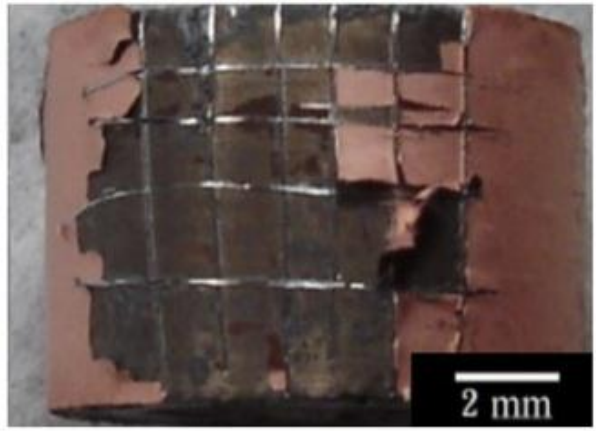

(a)

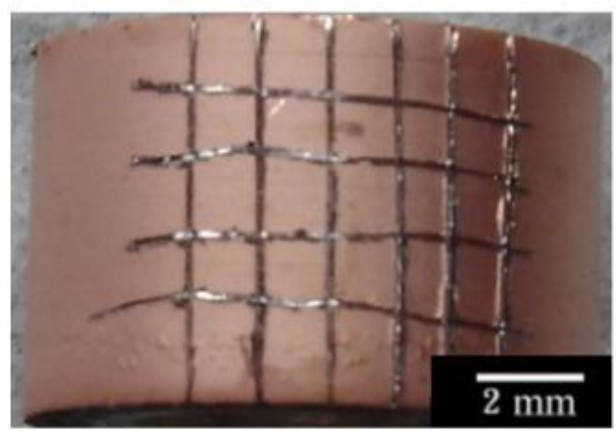

(b)

\subsection{Effect of Wetting on the Coverage of Cu Deposition Film}

The AZ80 RCE specimen with the U-shaped surface was vertically immersed in the alkaline $\mathrm{Cu}$ plating solution for galvanostatic etching and subsequent $\mathrm{Cu}$ plating. After galvanostatic etching to the potential plateau, the AZ80 specimen was electroplated in an alkaline $\mathrm{Cu}$ plating bath with a current density of $40 \mathrm{~mA} \cdot \mathrm{cm}^{-2}$ for $600 \mathrm{~s}$ and, subsequently, in the acidic $\mathrm{Cu}$ plating bath with a current density 
of $40 \mathrm{~mA} \cdot \mathrm{cm}^{-2}$ for $410 \mathrm{~s}$. From the cross-sectional micrographs shown in Figure $6 \mathrm{a}$, the $\mathrm{Cu}$ film does not evenly cover the inner upper side of the U-shaped surface after $\mathrm{Cu}$ electroplating in the alkaline $\mathrm{Cu}$ plating bath. In contrast, a uniform and fully covered $\mathrm{Cu}$ deposition film is observed on the AZ80 substrate in the inner bottom side of the U-shaped surface as shown in Figure 6b. The inner upper site of $\mathrm{U}$ shape, where was not well covered with $\mathrm{Cu}$, was not etched beforehand during galvanostatic etching and electroplating in the alkaline $\mathrm{Cu}$ plating bath. This finding indicates that a low corrosion rate for the AZ80 specimen can be expected in the alkaline $\mathrm{Cu}$ plating bath. Figure 6c, $\mathrm{d}$ show the cross-sections of the inner upper and bottom sites in the U-shaped surface of the Cu-deposited AZ80 specimen after $\mathrm{Cu}$ electroplating in the acidic $\mathrm{Cu}$ plating bath. The thickness of the $\mathrm{Cu}$ film increased markedly from 3 to approximately $9 \mu \mathrm{m}$ after electroplating in the acidic $\mathrm{Cu}$ plating bath. As shown in Figure $6 c$, the AZ80 specimen was obviously etched in the inner upper side of the U-shaped surface after $\mathrm{Cu}$ electrodeposition. In contrast, an evenly covered $\mathrm{Cu}$ deposit was observed at the inner bottom site of the U-shaped surface. Because the AZ80 specimen was electroplated in an alkaline and, subsequently, an acidic $\mathrm{Cu}$ plating bath, clear etching of the inner upper site of the U-shaped surface must have taken place during acidic $\mathrm{Cu}$ electroplating such that the $\mathrm{Cu}$ film on the AZ80 specimen could show an efficient increase in thickness. Although the AZ80 specimen was rotated at $1000 \mathrm{rpm}$, it is possible that some small gas bubbles were not excluded in the inner upper corner of the U-shaped surface during immersion and etching. Therefore, the surface activation of the inner upper U-shaped site was not achieved by using galvanostatic etching. That is, the AZ80 RCE with a U-shaped surface was not properly wetted because the specimen was vertically immersed during galvanostatic etching. To enhance the wetting properties of the AZ80 RCE with a U-shaped surface, the AZ80 specimen was tilted and rotated three times to properly wet the inner upper side of the U-shaped surface before galvanostatic etching.

Figure 6. Cross sections of the inner (a) upper and (b) bottom sites of U-shaped surface of AZ80 specimen after galvanostatic etching followed by $\mathrm{Cu}$ electroplating in the alkaline $\mathrm{Cu}$-plating bath and (c) and (d) the corresponding sites for the specimen after electroplating in an acidic $\mathrm{Cu}$ plating bath.

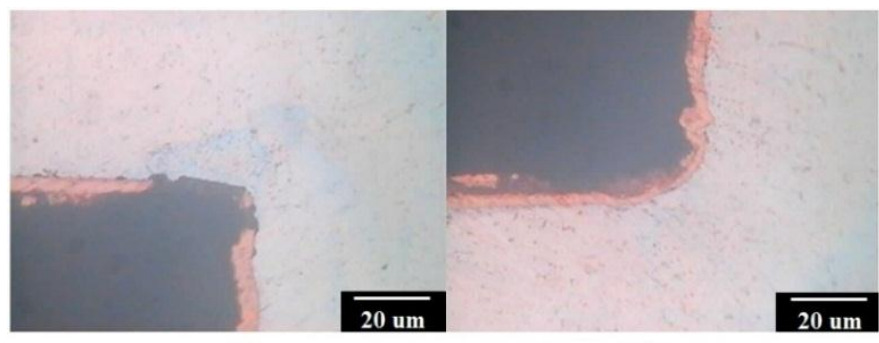

(a)

(b)

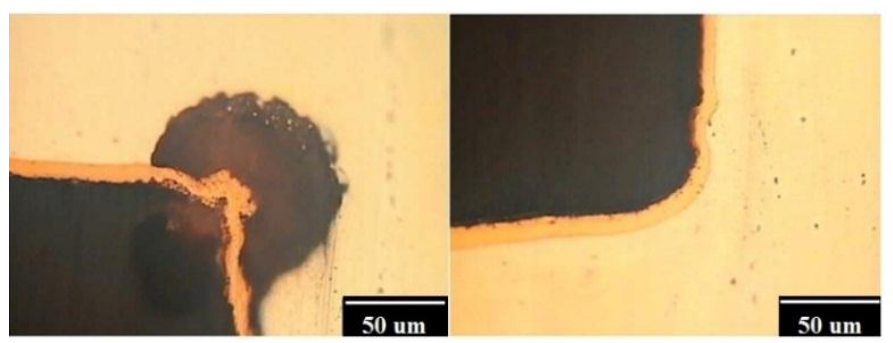

(c)

(d) 
Figure 7 shows the potential variation of properly and improperly wetted AZ80 RCEs with a U-shaped surface during galvanostatic etching for $120 \mathrm{~s}$. For the improperly wetted specimen, the anodic potential decreased rapidly from 6.4 to $4.4 \mathrm{~V}$ in the first $10 \mathrm{~s}$ and gradually decreased to $3.8 \mathrm{~V}$ in the subsequent galvanostatic etching. The potential plateau was not observed from the anodic potential variation during galvanostatic etching although the rotation speed of AZ80 specimen was maintained at $1000 \mathrm{rpm}$. This result indicates that the surface activation was not sufficient because the potential did not reach the lower regime for effective etching. The high potential in the beginning of galvanostic etching could be attributed to the improperly wetted AZ80 specimen. This would result from the presence of few bubbles with high impedances in the inner corners. In contrast, for a properly wetted AZ80 specimen, as shown in Figure 7, the anodic potential was steady at $1.55 \mathrm{~V}$ in the first $60 \mathrm{~s}$ and increased almost linearly to $3.75 \mathrm{~V}$ when galvanostatic etching was performed from 60 to $90 \mathrm{~s}$ and finally remained at $3.75 \mathrm{~V}$, the potential plateau, until $180 \mathrm{~s}$. The potential variation between the improperly and properly wetted AZ80 specimens is notably different. This finding means that the effect of galvanostatic etching on the AZ80 surface can be controlled by the degree of wetting. Moreover, the wetting effect (improper or proper wetting) could be observed from the potential variation during galvanostatic etching as shown in Figure 7.

Figure 7. Potential variation of improperly and properly wetted AZ80 specimens with a U-shaped surface at a rotation speed of $1000 \mathrm{rpm}$ during galvanostatic etching at the current density of $20 \mathrm{~mA} \cdot \mathrm{cm}^{-2}$ in an alkaline Cu-plating bath.

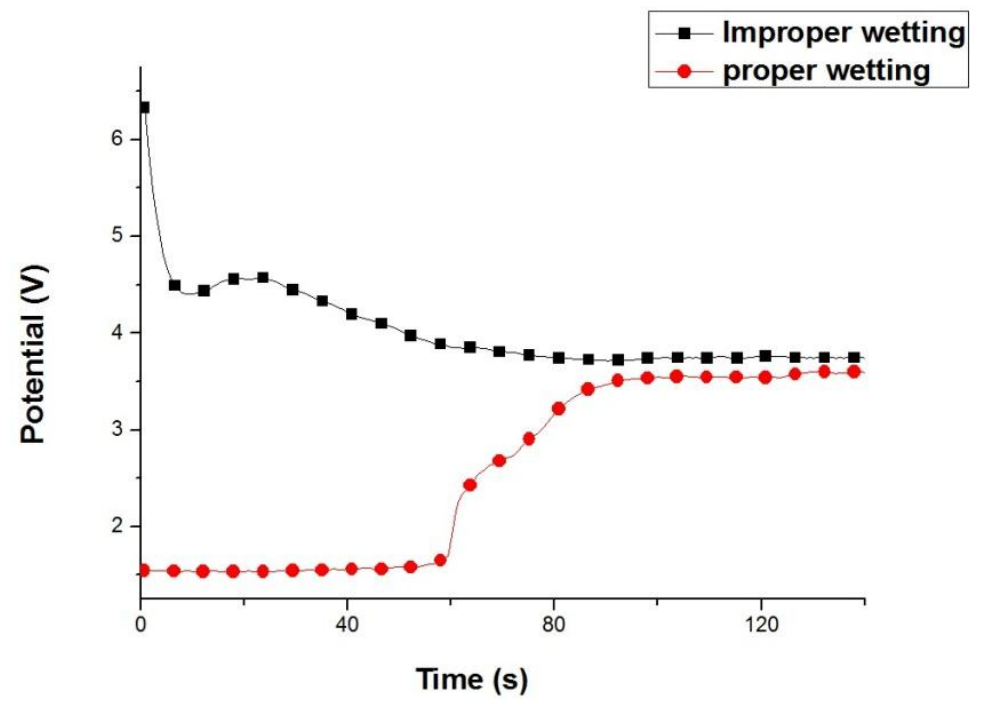

Figure 8a,b shows the cross-sections of the inner upper sites in the U-shaped surface that was properly wetted, galvanostatically etched, and electroplated in an alkaline and, subsequently, an acidic $\mathrm{Cu}$ plating bath. As expected, a uniform and evenly covered $\mathrm{Cu}$ deposition film was observed in the inner upper sites of the U-shaped surface. This result means that proper wetting is needed for $\mathrm{Cu}$ electrodeposition on the AZ80 RCE with a U-shaped surface. An increase in the anodic potential to a potential plateau could be regarded as a suitable galvanostatic etching environment for obtaining an activated surface for further $\mathrm{Cu}$ electrodeposition. With proper wetting and galvanostatic etching, the AZ80 RCE with a multi-V shaped surface that resembles a screw shape could be uniformly electroplated as shown in Figure 9a,b. This finding indicates that $\mathrm{Cu}$ electroplating on $\mathrm{Mg}$ alloy 
components with $\mathrm{U}$ and $\mathrm{V}$ shapes is feasible. Because the AZ80 RCE with a U- or V-shaped surface could be activated and electroplated in the alkaline $\mathrm{Cu}$ plating bath, a $\mathrm{Cu}$-treated AZ80 specimen could be the substrate for further $\mathrm{Ni}$ electroplating to obtain a protective $\mathrm{Ni} / \mathrm{Cu}$ coating.

Figure 8. Cross sections of the inner upper sites of the U-shape surface of AZ80 specimens after proper wetting and galvanostatic etching followed by $\mathrm{Cu}$ electroplating in (a) an alkaline and, subsequently; (b) an acidic $\mathrm{Cu}$ plating bath.

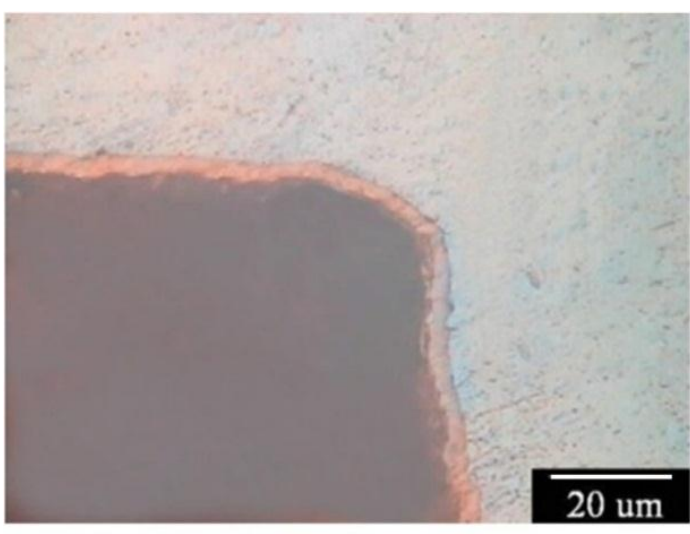

(a)

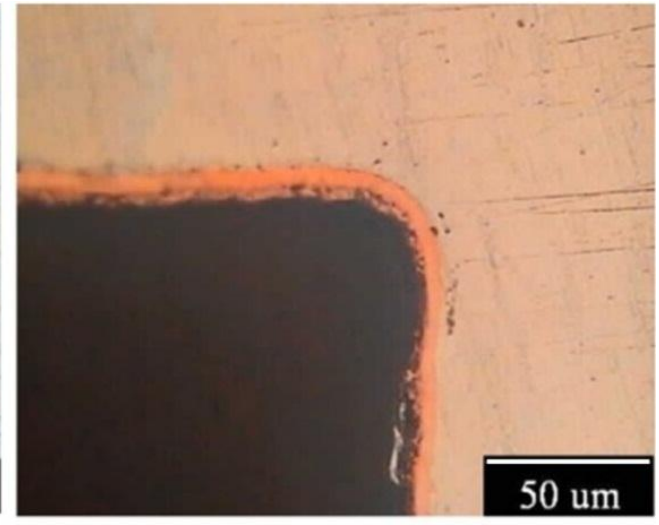

(b)

Figure 9. Optical micrographs of (a) overview and (b) cross section of the Cu-deposited AZ80 specimen with a multi-V shape.

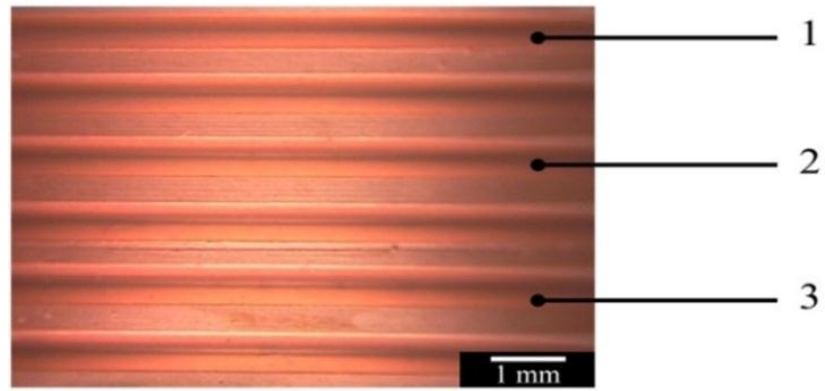

(a)

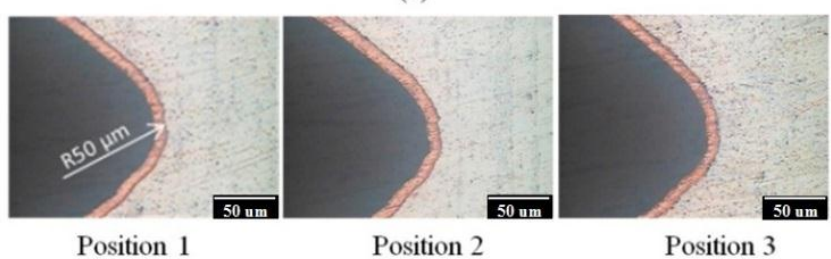

(b)

\subsection{Electrochemical Test for Corrosion}

Figure 10 shows the anodic polarisation behaviour of uncoated and $\mathrm{Cu}$-coated AZ80 specimens, which were galvanostatically etched and then electroplated in the alkaline and acidic $\mathrm{Cu}$ plating baths at different rotational speeds in a $0.1 \mathrm{M} \mathrm{H}_{2} \mathrm{SO}_{4}$ solution. The corrosion potential of the AZ80 RCE with a U-shaped surface was $-1.74 \mathrm{~V}(v s . \mathrm{Ag} / \mathrm{AgCl})$, and its corrosion current density was $2 \times 10^{-3} \mathrm{~A} \cdot \mathrm{cm}^{-2}$. The corrosion potential increased markedly to approximately $-0.45 \mathrm{~V}$ ( $v s$. $\mathrm{Ag} / \mathrm{AgCl}$ ), and the corrosion current density of the AZ80 specimen was reduced to approximately $1 \times 10^{-4} \mathrm{~A} \cdot \mathrm{cm}^{-2}$ after $\mathrm{Cu}$ 
electroplating. It must be noted that the anodic current density of the Cu-treated AZ80 specimen prepared at $500 \mathrm{rpm}$ is much higher than that of the specimen prepared at a rotation speed of $1000 \mathrm{rpm}$ or greater. This result means that the corrosion resistance of the former is worse than that of the latter. This finding is also in agreement with the results from the bonding strength test and galvanostatic etching in which a well-adhered $\mathrm{Cu}$ film on the AZ80 RCE with a U-shaped surface can only be obtained when the rotation speed is $1000 \mathrm{rpm}$ or greater. To examine the bonding between the $\mathrm{Cu}$ deposit and the AZ80 specimen prepared at $500 \mathrm{rpm}$, the cross section of the $\mathrm{Cu}$-treated U-shaped surface was examined. As shown in Figure 11a,b, the inner lower and upper sites of U-shaped were strongly etched after $\mathrm{Cu}$ electroplating in the acidic $\mathrm{Cu}$-plating bath. This result means that the $\mathrm{Cu}$-coated AZ80 specimen prepared at $500 \mathrm{rpm}$ has a lower corrosion resistance. This finding explains why the anodic current density was much greater than that of the $\mathrm{Cu}$-coated AZ80 specimen prepared at $1000 \mathrm{rpm}$ or greater.

Figure 10. Anodic polarisation curves of uncoated and Cu-coated AZ80 RCEs with a U-shaped surface galvanostatically etched and $\mathrm{Cu}$-electroplated at different rotation speeds in the alkaline bath.

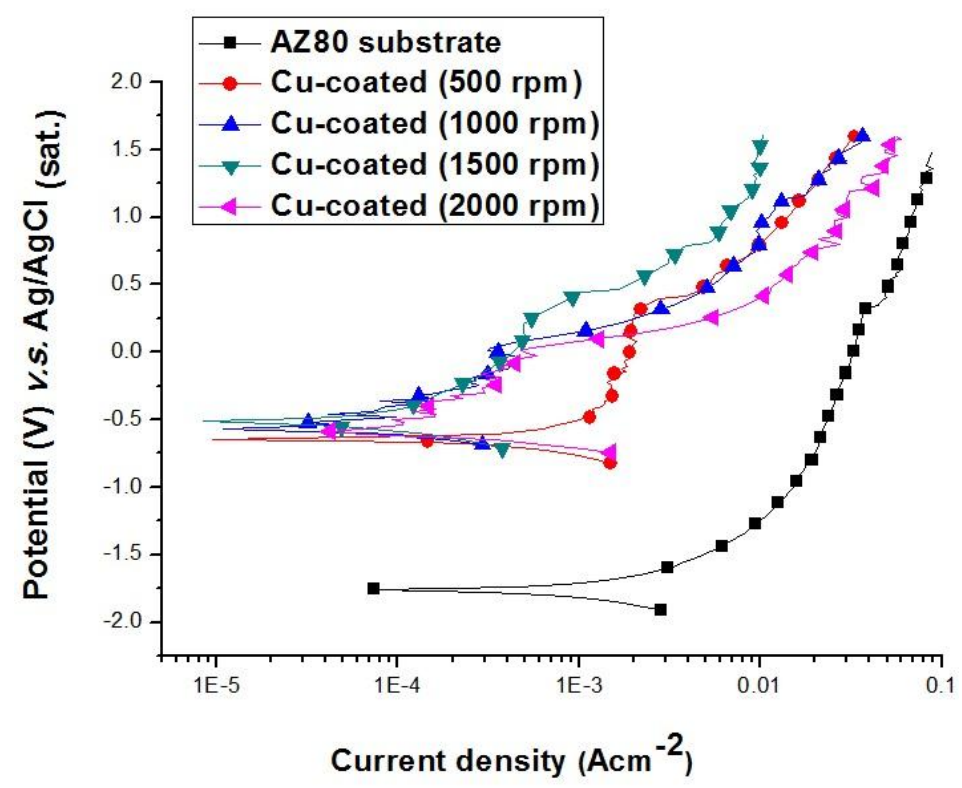

Figure 11. Cross sections of the inner (a) lower and (b) upper sites of U-shape surface of AZ 80 specimen prepared at a rotation speed of $500 \mathrm{rpm}$ after $\mathrm{Cu}$ electrodeposition in the acidic $\mathrm{Cu}$-plating bath.

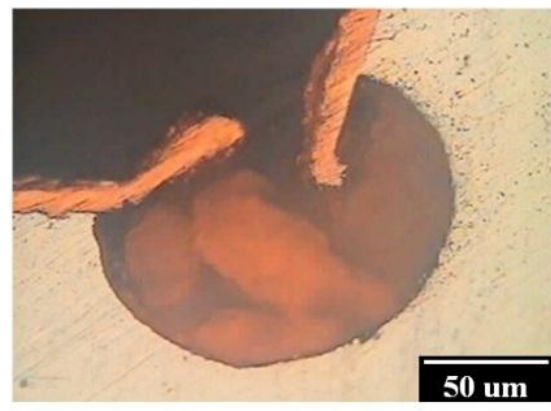

(a)

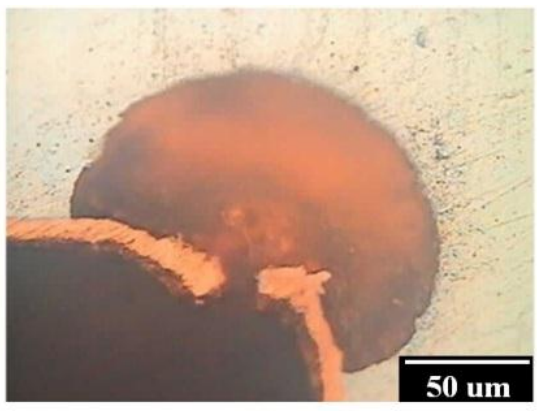

(b) 
Figure 12 shows the anodic polarisation curves of the AZ80 specimen and the Cu-coated and $\mathrm{Ni} / \mathrm{Cu}$-coated AZ80 specimens in the $0.1 \mathrm{M} \mathrm{H}_{2} \mathrm{SO}_{4}$ solution. The corrosion potential of the AZ80 specimen increased to $0.4 \mathrm{~V}$ (vs. $\mathrm{Ag} / \mathrm{AgCl}$ ), and its corrosion current density decreased to $5 \times 10^{-7} \mathrm{~A} \cdot \mathrm{cm}^{-2}$ upon $\mathrm{Cu}$ and $\mathrm{Ni}$ electroplating. The corrosion resistance of the Cu-treated AZ80 specimen is significantly improved after $\mathrm{Ni}$ electroplating. That is, the AZ80 specimen with a $\mathrm{U}$-shaped surface could be $\mathrm{Cu}$ - and Ni-electroplated to increase its corrosion resistance.

Figure 12. Anodic polarisation curves of $\mathrm{Ni} / \mathrm{Cu}-, \mathrm{Cu}$-coated and uncoated AZ80 specimens with a U-shaped surface at a rotation speed of $1000 \mathrm{rpm}$.

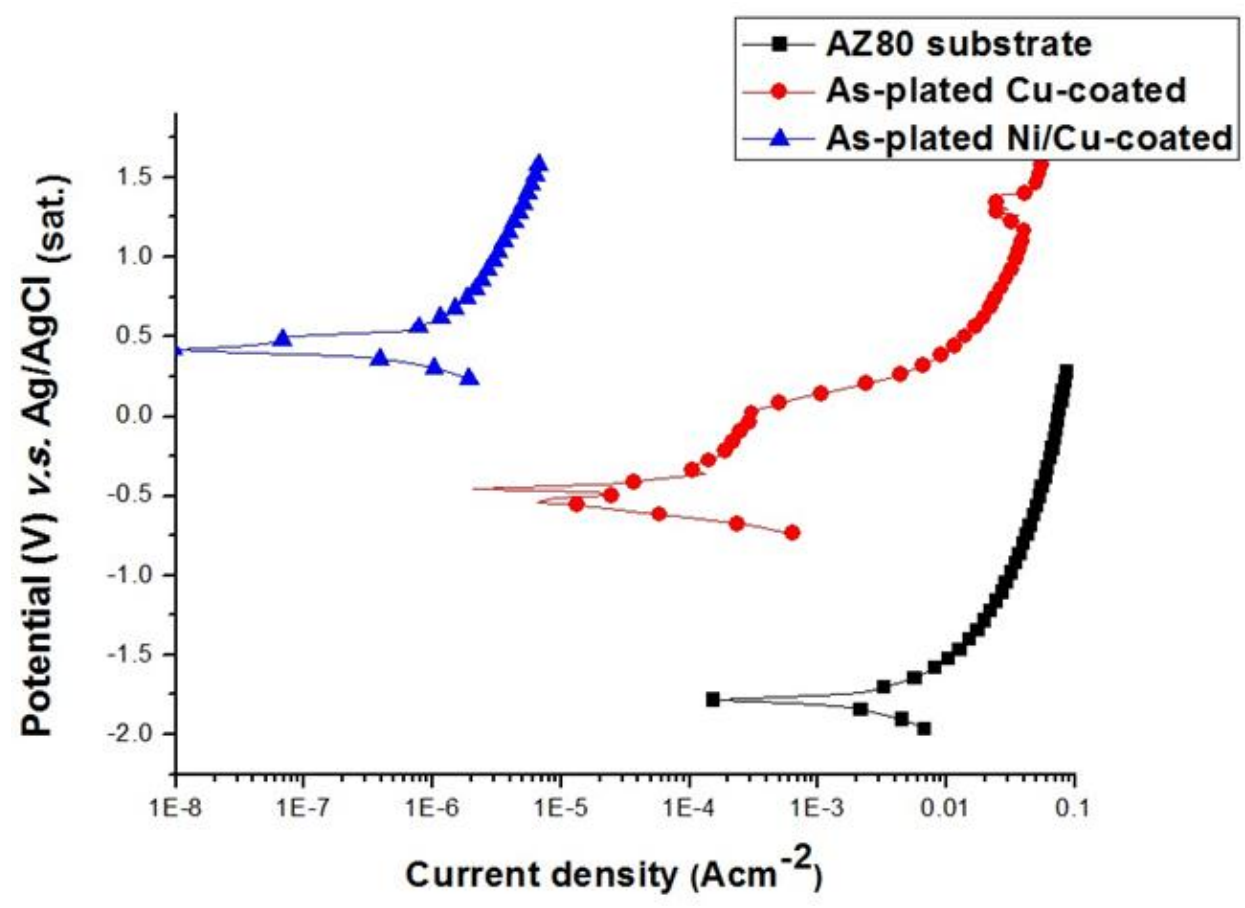

\section{Conclusions}

$\mathrm{Cu}$ electrodeposition was performed on a magnesium alloy (AZ80) of a cylindrical shape with or without a U-shaped surface. Experimental results demonstrated that a uniform $\mathrm{Cu}$ film could be produced on the AZ80 specimen through galvanostatic etching followed by $\mathrm{Cu}$ electroplating in an alkaline $\mathrm{Cu}$ plating bath. An uncovered $\mathrm{Cu}$ deposit was observed at the inner upper site of the U-shaped surface of AZ80 electrode when the specimen was improperly wetted and rotated at a speed of $500 \mathrm{rpm}$ or lower. The wetting effect on the U-shape surface of AZ80 electrode could be detected from the variation in anodic potential during galvanostatic etching in the alkaline $\mathrm{Cu}$ plating bath. The corrosion resistance of $\mathrm{Cu}$-coated AZ80 can be significantly improved upon Ni electroplating.

\section{Acknowledgments}

The authors would like to thank the National Science Council of the China (ROC) for providing support for this work under contract No. 98-2221-E-182-016-MY3. 


\section{Author Contributions}

Ching An Huang proposed the idea of $\mathrm{Cu}$ electrodeposition on a AZ80 Mg alloy with or without a U-shaped surface and wrote most of the article. Yu Hu Yeh, Che Kuan Lin, and Chen Yun Hsieh conducted the related experiments. All authors extensively discussed the details of all experimental results and finalized the article.

\section{Conflicts of Interest}

The authors declare no conflict of interest.

\section{References}

1. Schmutz, P.; Guillaumin, V.; Lillard, R.S.; Lillard, J.; Frankel, G.S. Influence of dichromate ions on corrosion processes on pure magnesium. J. Electrochem. Soc. 2003, 150, B99-B110.

2. Gray, J.E.; Luan, B. Protective coatings on magnesium and its alloys-A critical review. J. Alloy. Compd. 2002, 336, 88-113.

3. Yin, T.T.; Wu, R.Z.; Leng, Z.; Du, G.J.; Guo, X.Y.; Zhang, M.L.; Zhang, J.H. The process of electroplating with $\mathrm{Cu}$ on the surface of Mg-Li alloy. Surf. Coat. Technol. 2013, 225, 119-125.

4. Chong, K.Z.; Shih, T.S. Conversion-coating treatment for magnesium alloys by a permanganate-phosphate solution. Mater. Chem. Phys. 2003, 80, 191-200.

5. Phuong, N.V.; Moon, S. Effect of microstructure on the zinc phosphate conversion coatings on magnesium alloy AZ91. Appl. Surf. Sci. 2013, 264, 70-78.

6. Mizutani, Y.; Kim, S.J.; Ichino, R.; Okido, M. Anodizing of Mg alloys in alkaline solutions. Surf. Coat. Technol. 2003, 169, 143-146.

7. Xia, Y.H.; Zhang, B.P.; Lu, C.X. Improving the corrosion resistance of Mg-4.0Zn-0.2Ca alloy by micro-arc oxidation. Mater. Sci. Eng. C 2013, 33, 5044-5050.

8. Durdu, S.; Usta, M. Characterization and mechanical properties of coatings on magnesium by microarc oxidation. Appl. Surf. Sci. 2012, 261, 774-782.

9. Barranco, V.; Carmona, N.; Galvan, J.C.; Grobelny, M.; Kwiatkowski, L.; Villegas, M.A. Electrochemical study of tailored sol-gel thin films as pre-treatment prior to organic coating for AZ91 magnesium alloy. Prog. Org. Coat. 2010, 68, 347-355.

10. Rie, K.-T.; Wöhle, J. Plasma-CVD of TiCN and ZrCN films on light metals. Surf. Coat. Technol. 1999, 112, 226-229.

11. Ambat, R.; Zhou, W. Electroless nickel-plating on AZ91D magnesium alloy: Effect of substrate microstructure and plating parameters. Surf. Coat. Technol. 2004, 179, 124-134.

12. Liu, Z.; Gao, W. Electroless nickel plating on AZ91 Mg alloy substrate. Surf. Coat. Technol. 2006, 200, 5087-5093.

13. Huang, C.A.; Wang, T.H.; Weirich, T.; Neubert, V. A pretreatment with galvanostatic etching for copper electrodeposition on pure magnesium and magnesium alloys in an alkaline copper-sulfate bath. Electrochim. Acta 2008, 53, 7325-7241.

14. Huang, C.A.; Wang, T.H.; Weirich, T.; Neubert, V. Electrodeposition of a protective copper/nickel deposit on the magnesium alloy (AZ31). Corros. Sci. 2008, 50, 1385-1390. 
15. Huang, C.A.; Lin, C.K.; Yeh, Y.H. Increasing the wear and corrosion resistance of magnesium alloy (AZ91D) with electrodeposition from eco-friendly copper- and trivalent chromium-plating baths. Surf. Coat. Technol. 2010, 205, 139-145.

16. ISO 2409, Technical Committee ISO/TC 35, Paints and Varnishes, General Test for Paints and Varnishes; International Organization for Standardization: Geneva, Switzerland, 2007.

(C) 2014 by the authors; licensee MDPI, Basel, Switzerland. This article is an open access article distributed under the terms and conditions of the Creative Commons Attribution license (http://creativecommons.org/licenses/by/4.0/). 